and excluding participants with prescriptions for iodine-containing drugs or history of thyroid cancer (e.g. non-autoimmune cause of thyroxin use). We used a casecontrol design with thyroxin substitution as exposure, cases defined as EULAR DAS28 3- and 6-month non-responders, and controls defined as moderate/good responders at these time-points. Odds Ratios (OR) were calculated adjusted for sex, age, and $\mathrm{HAQ}$.

Results: At 3 months, the proportion of thyroxin users did not differ between responders and non-responders $12 \%$ vs. $11 \%$, (OR non-response $=1.1,95 \% \mathrm{Cl}$ $0.9-1.4$ ). At 6 months, the corresponding figures were $13 \%$ vs. $11 \%$, respectively, (OR non-response $=1.3,95 \% \mathrm{Cl} 1.0-1.7$ ). However, a significant difference was observed in RF and/or ACPA positive patients at 6 months, where $15 \%$ of non-responders and $10 \%$ of responders used thyroxin (OR non-response $=1.6$, $95 \% \mathrm{Cl}$ 1.1-2.1), while no such difference was observed for seronegative RA. When stratified for gender, thyroxin substitution was significantly associated with non-response in men but not in women.

Table 1. Relative risk of prevalent AITD before RA-diagnosis in non-responders compared to moderate and good responders according to EULAR response criteria, at the 6 month follow-up visit among 3148 RA-patients starting methotrexate as first ever DMARD

\begin{tabular}{lcc}
\hline & $\begin{array}{c}\text { No of AITD in non-responders (718)/ } \\
\text { moderate and good responders }(887+1543)\end{array}$ & Adj. OR (95\% Cl) \\
\hline $\begin{array}{l}\text { Overall } \\
\text { Sex }\end{array}$ & $93(13 \%) / 254(11 \%)$ & $1.28(0.98-1.66)$ \\
$\quad$ Women & $81(16 \%) / 231(14 \%)$ & $1.19(0.89-1.57)$ \\
$\quad$ Men & $12(5.6 \%) / 23(2.8 \%)$ & $2.20(1.05-4.60)$ \\
Serostatus & $73(15 \%) / 163(10 \%)$ & $1.57(1.14-2.14)$ \\
$\quad$ RF and/or ACPA positive & $20(8.9 \%) / 80(11 \%)$ & $0.82(0.48-1.42)$ \\
$\quad$ RF and ACPA Negative & $0 / 11$ & NA \\
\hline Serostatus unspecified & &
\end{tabular}

Values are the number. RA = rheumatoid arthritis; AITD = autoimmune thyroid disease; OR = odds ratio; $95 \% \mathrm{Cl}=95 \%$ confidence interval.

Conclusions: This large real-life study of response to methotrexate in early RA suggests that AITD, measured as thyroxin replacement therapy, may be linked to treatment response in seropositive patients (and among males). Exploratory by nature, these findings call for replication.

Disclosure of Interest: K. Waldenlind: None declared, S. Saevarsdottir: None declared, C. Bengtsson: None declared, J. Askling Grant/research support from: Abbvie, Pfizer, Lilly, Samsung, MSD, UCB, Roche, Janssen

DOI: 10.1136/annrheumdis-2017-eular.3725

\section{FRI0150 EPIDEMIOLOGICAL DESCRIPTION OF PSYCHOLOGICAL, SEXUAL AND SLEEP DISORDERS IN PATIENTS WITH RHEUMATOID ARTHRITIS AND CORRELATION BETWEEN THEM AND DISEASE ACTIVITY}

L. Villarreal ${ }^{1}$, S. Henao ${ }^{2}$, D. Buitrago-Garcia ${ }^{3}$, P. Santos-Moreno ${ }^{4} .{ }^{1}$ Psychology and processes; ${ }^{2}$ Patient service; ${ }^{3}$ Epidemiology; ${ }^{4}$ Rheumatology, Biomab, Center for Rheumatoid Arthritis, Bogota, Bogota, Colombia

Background: Rheumatoid arthritis (RA) is the prevalent autoimmune inflammatory arthritis found in adults, with the worldwide prevalence ranging from $0.4 \%$ to $1.3 \%$. Psychological disorders can be underestimated in this population; on the other hand studies had shown that the daily experience with RA can lead to sleep, psychological and sleep disorders.

Objectives: To characterize a population with RA and to describe the psychological, sexual and sleep disorders in a specialized rheumatology center in Bogotá Colombia.

Methods: We perform a cross-sectional study of patients attending to our psychology consultation the information was collected through semi-structured interviews, also using classificatory criteria of pathologies described in CIE 10 diagnostic manual, applying descriptive epidemiology for continuous variables, measure of central tendency and dispersion for qualitative and categorical variables through percentages and averages.

Results: We included 1398 patients attending to our psychology consultation. Mean age was 55 years $\pm 8 ; 80 \%$ were female and $20 \%$ male. Mean DAS28 was $2.6 \pm 1.3$, mean $\mathrm{HAQ}$ was 1.6 \pm 1.6 ; patients had the disease for an average of 12 years $+8 ; 41 \%$ of patients had comorbidities associated with non-autoimmune disease, $14 \%$ comorbidities related to autoimmune disease; $35 \%$ of our patients did not report other comorbidities. Most of patients were married $60 \%$, followed by divorced $19 \%$, single $14 \%$ and widowed $7 \%$. Regarding occupation $33 \%$ were employees, $25 \%$ were housekeepers or retired due to age, $12 \%$ were retired due to disabilities, and $3 \%$ unemployed. Of the total population $45 \%$ had elementary school, $32 \%$ high school, $8 \%$ college education, $7 \%$ graduate education and $7 \%$ were illiterate. $17 \%$ of patients lived alone. Regarding psychological factors $25 \%$ had any mood disorders, $13 \%$ sleep disorders, $12 \%$ somatomorphic disorders, $6 \%$ sexual dysfunction, $2 \%$ dementia, $4 \%$ eating disorders and $38 \%$ reported no to have any of the above. Concerning sexual disorders, $38 \%$ reported no to have any sexual activity, $32 \%$ reported to have a satisfactory sexual life, $11 \%$ dyspareunia, $9 \%$ had an unsatisfactory sexual life, $5 \%$ loss of desire, $3 \%$ premature ejaculation and $2 \%$ orgasmic decrease. When the psychologist asked about sleep disorders $69 \%$ reported no to have any, $25 \%$ primary insomnia, $1 \%$ hypersomnia, $3 \%$ OSAS and $2 \%$ alterations on the circadian rhythm. There was a statistical association between psychological and sexual disorders, sleep and sexual disorders and, psychological and sleep disorders. Disease activity was associated only with sleep disorders.

Conclusions: Not only DMARDs disease management should be a priority for RA patients, factors such as sleep, sexual and psychological are important because one third of patients have it; on the other hand there is a interdependence between them and disease activity. Thus, it is important to have a multidisciplinary care team for the patient with RA, including a psychologist that can manage this kind of conditions and if necessary refer to a psychiatrist consultation.

Disclosure of Interest: None declared

DOI: 10.1136/annrheumdis-2017-eular.5622

\section{FRI0151 DISEASE COURSE IN SERONEGATIVE RA PATIENTS CLASSIFIED ACCORDING TO THE 2010 ACR/EULAR CRITERIA}

L.B. Nordberg ${ }^{1}$, S. Lillegraven ${ }^{1}$, A.-B. Aga ${ }^{1}$, I.C. Olsen ${ }^{1}$, E. Lie ${ }^{1}$, H.B. Hammer ${ }^{1}$, T. Uhlig ${ }^{1}$, D. van der Heijde ${ }^{2}$, T.K. Kvien ${ }^{1}$, E.A. Haavardsholm ${ }^{1}$ on behalf of the ARCTIC study group. ${ }^{1}$ Diakonhjemmet Hospital, oslo, Norway; ${ }^{2}$ Leiden University medical center, Leiden, Netherlands

Background: The development of the 2010 classification criteria for rheumatoid arthritis (RA) has led to a redefinition of the patient population, including classification of seropositive versus seronegative patients. In our recently published study of DMARD naîve early RA patients fulfilling the 2010 ACR/EULAR criteria, we found seronegative patients to have markedly higher disease activity at time of diagnosis, compared to seropositive patients.[1] There is very limited information about the disease course of seronegative patients classified according to the new criteria.

Objectives: Our aim was to examine the disease course of seronegative early RA patients fulfilling the 2010 ACR/EULAR criteria.

Methods: In the treat-to-target ARCTIC trial, DMARD-naive RA patients classified according to the 2010 EULAR/ACR criteria were randomised 1:1 to follow-up with or without ultrasound. Patients in both arms were treated according to the same DMARD escalation strategy. Patients were assessed at 13 visits during two years of follow-up.[2] We stratified the patients as seropositive (rheumatoid factor $(\mathrm{RF})+$, anti-citrullinated peptide antibody (ACPA)+, or both) or seronegative (RFand ACPA-). At 24-month follow-up, measures of disease activity were compared across the groups using independent samples t-test, Mann-Whitney $\mathrm{U}$ test or chi square test as appropriate.

Results: A total of 230 patients were included, the mean (SD) age was 51.4 (13.7) years and $61.3 \%$ were female; 34 patients $(14.8 \%)$ were seronegative. The mean age (SD) was $55.4(2.7) / 50.8(0.9)$ years $(\mathrm{p}=0.07)$, mean (SD) disease duration was $7.7(6.8) / 7.0(5.1)$ months $(p=0.46)$, and $56 / 62 \%$ were females $(p=0.48)$ in the seronegative/seropositive groups. At 24 -month follow-up, measures of disease activity were similar between groups (table). There was a tendency towards more radiographic damage in the seronegative patients. Seronegative patients had a significantly greater reduction (0-24 months) in disease activity measures in terms of DAS, number of swollen joints, physician global and ultrasonography scores (table).

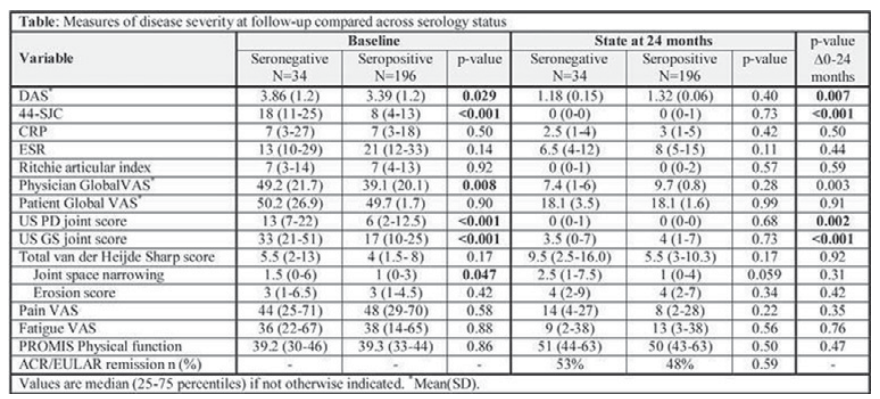

Conclusions: In this study of early RA patients, seronegative patients had more inflammatory activity at baseline and a tendency to more radiographic damage, but disease activity after two years of treat-to-target therapy was similar to the seropositive patients. Our findings suggest that seronegative patients classified according to the new criteria respond to modern treatment strategies, with similar rates of patients reaching remission compared to seropositive patients.

References:

[1] Nordberg LB et al. Annals of the rheumatic diseases 2017;76:341-345.

[2] Haavardsholm EA et al., BMJ 2016;354:i4205.

Disclosure of Interest: L. Nordberg: None declared, S. Lillegraven: None declared, A.-B. Aga: None declared, I. Olsen: None declared, E. Lie: None declared, H. Hammer Consultant for: AbbVie, Pfizer, BMS, Roche, UCB, T. Uhlig: None declared, D. van der Heijde: None declared, T. Kvien: None declared, E. Haavardsholm Grant/research support from: Pfizer, MSD, UCB, AbbVie, Roche DOI: 10.1136/annrheumdis-2017-eular.4967 